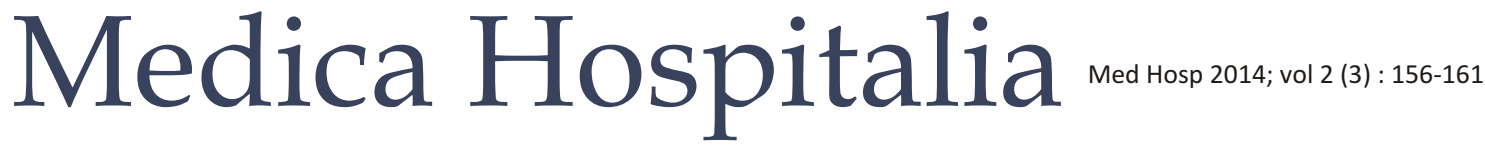

Original Article

\section{Efektivitas Fruit Frozen terhadap Keluhan Haus dan Mulut Kering pada Pasien CHF yang Menjalani Program Restriksi Cairan di Ruang UPJ RSUP Dr. Kariadi Semarang}

\author{
Muh. Mukhlis Sujudi*, Amin Zuhri**, Ari Kusumantoro*** \\ *Kepala Ruang UPJ, **Perawat Pelaksana Ruang UPJ, ***Perawat Primer Ruang UPJ - RSUP Dr. Kariadi Semarang
}

\begin{abstract}
Abstrak
Latar belakang : Keadaaan hipervolemia pada pasien CHF akan meningkatkan kerja jantung dan meningkatkan tekanan hidrostatik yang pada akhirnya akan terjadi edema baik anasarka maupun edema paru. Penatalaksanaan pemberian kombinasi diuretik, ACE inhibitor dan beta-blocker akan meningkatkan rasa haus dan kekeringan pada mulut. Untuk mengatasi keluhan tersebut maka intervensi pemberian fruit frozen dipilih berdasarkan rekomendasi bahwa pasien dengan CHF dapat mengkonsumsi semua buah buahan dan sayuran segar. Tujuan penelitian ini mengetahui efektivitas pemberian fruit frozen terhadap keluhan haus dan mulut kering pada pasien $\mathrm{CHF}$ yang menjalani program restriksi cairan.

Metode : Penelitian ini merupakan penelitian kuantitatif dengan desain eksperimen semu (quasi experiment) dengan rancangan penelitian ini ialah one group pretest posttest. Populasi dalam penelitian ini adalah semua pasien dengan diagnosa medis $\mathrm{CHF}$ NYHA II-IV di ruang ruang UPJ RSUP Dr. Kariadi Semarang dan pengambilan sampel dilakukan dengan metode purposive sampling yaitu berjumlah 30 orang. Variabel yang dikaji dalam penelitian ini adalah rasa haus dan mulut kering pasien sebelum dan setelah diberikan fruit frozen. Analisa data yang digunakan dalam penelitian ini adalah dengan menggunakan analisis statistik Wilcoxon dan Tdependent/Paired T-test.

Hasil : Berdasarkan hasil analisis statistik didapatkan bahwa ada efektivitas yang signifikan antara tingkat rasa haus dan mulut kering sebelum dan sesudah diberikan fruit frozen pada pasien CHF yang menjalani restriksi cairan dengan $p=0,000<\alpha(0,05)$. Simpulan : Berdasarkan hasil analisis statistik tersebut maka diharapkan perawat dapat melaksanakan dan meningkatkan kinerja dalam melakukan monitoring dan evaluasi program restriksi cairan dengan pemberian supporting therapy melalui pemberian fruit frozen secara berkelanjutan pada setiap pasien CHFyang menjalani program restriksi cairan.
\end{abstract}

Kata kunci : rasa haus dan mulut kering, fruit frozen, $\mathrm{CHF}$

\section{Effectiveness of Frozen Fruit and Dry Mouth Thirsty Grievance on CHF Patients Undergoing The Fluid Restriction Program in Cardiac Service Unit (CSU) of Dr. Kariadi Hospital Semarang}

\section{Abstract}

Background : Circumstances hypervolemia in patients with $\mathrm{CHF}$ will increase work load of the heart and the hydrostatic pressure that will eventually happen either anasarka edema and pulmonary edema. The management of administration of a diuretics combination, ACE inhibitors and beta - blockers will increase thirst and dry mouth. To solve these complaints, frozen fruit are selected based on the recommendation that patients with CHF can consume all the fresh fruits and vegetables. The purpose of this study examine the effectiveness of the frozen fruit of thirst and dry mouth in CHF patients undergoing fluid restriction. This is a quantitative study with a quasi-experimental design with one group pretest posttest.

Methods: The population in this study were all patients with a medical diagnosis CHF NYHA II-IV in the spaces CSU of Dr. Kariadi Semarang and with a purposive sampling method were 30 . The variables that were examined in this study were thirst and dry mouth patients before and after administration of frozen fruit. A Wilcoxon and T dependent/paired T-test is used to analyse the data.

Results : Based on the results of statistical analysis showed that there was significant correlation between the level of effectiveness of thirst and dry mouth before and after the frozen fruit in CHF patients who underwent fluid restriction with $p=0.000$ $<\alpha(0.05)$.

Conclusion : Based on the results of the statistical analysis it is expected that nurses can implement and improve the performance of the monitoring and evaluation of the program by providing a supporting fluid restriction therapy by providing frozen fruit in a sustainable manner at any CHF patients undergoing fluid restriction.

Keywords: Thirst and dry mouth, fruit frozen, $\mathrm{CHF}$ 


\section{PENDAHULUAN}

Congestive Heart Failure (CHF) atau gagal jantung kongestif merupakan suatu kondisi klinis akhir dari berbagai penyakit jantung seperti infark miokard, penyakit jantung koroner, gangguan katup, hipertensi, dan kelainan jantung bawaan. ${ }^{15}$ Kondisi gagal jantung tersebut akan menyebabkan adanya penurunan kardiak output. Penurunan kardiak output tersebut akan direspon oleh tubuh dengan serangkaian mekanisme kompensasi yang ditujukan untuk memenuhi kebutuhan sirkulasi dan perfusi jaringan.

Prevalensi Heart Failure di Amerika dan Eropa sekitar 1-2\%. Diperkirakan bahwa 5,3 juta warga Amerika saat ini mengidap CHF dan setidaknya ada 550.000 kasus Heart Failure baru yang didiagnosis setiap tahunnya. ${ }^{1,15}$ Prevalensi CHF meningkat seiring dengan usia, dan mempengaruhi 6-10\% individu lebih dari 65 tahun. ${ }^{15}$ Di Indonesia, belum ada gambaran pasti tentang prevalensi CHF. Kunjungan di RS Jantung Harapan Kita, setiap hari ada sekitar 400-500 pasien berobat jalan, dan sekitar $65 \%$ adalah pasien $\mathrm{CHF}^{11}$

Berdasarkan data kasus sepuluh besar di ruang rawat inap Unit Pelayanan Jantung (UPJ) RSUP Dr. Kariadi, didapatkan bahwa kasus CHF menduduki peringkat pertama dari seluruh kasus jantung di ruang tersebut. Hal ini ditunjukkan dengan jumlah kasus CHF mencapai lebih dari $60 \%$ dari total pasien.

Pasien dengan CHF mengalami penurunan kardiak output yang menyebabkan penurunan perfusi organ yang akan direspon oleh tubuh dengan meningkatkan volume cairan tubuh melalui mekanisme sistem Renin-Angiotensin-Aldosteron. Angiotensin II memiliki beberapa efek fisiologi antara lain vasokonstriksi pembuluh darah ginjal dan perifer, menstimulasi sistem saraf simpatis dan meningkatkan rasa haus. ${ }^{1,4,15}$

Angiotensin II juga meningkatkan sintesa aldosteron yang memicu reabsorbsi natrium dan menahan natrium pada ginjal. Keadaan ini akan membuat tubuh berada pada kondisi hipervolemia. Keadaaan hipervolemia pada pasien CHF akan meningkatkan kerja jantung dan meningkatkan tekanan hidrostatik yang pada akhirnya akan terjadi edema baik anasarka maupun edema paru. Upaya untuk mencegah terjadinya peningkatan beban kerja jantung dan terjadi edema dapat dilakukan secara farmakologis dan non farmakologis. Penatalaksanaan tersebut dapat berupa pemberian diuretik dan modifikasi lifestyle. Pada pemberian kombinasi diuretik, ACE inhibitor dan betablocker akan meningkatkan kekeringan pada mulut. Masalah mulut kering dirasakan lebih berat pada saat siang hari. ${ }^{13}$

Rasa haus dan mulut kering merupakan persepsi subyektif yang menimbulkan rasa kesegeraan untuk minum. ${ }^{19}$ Dengan adanya keluhan ini dapat menimbulkan ketidaknyamanan dan memicu ketidakpatuhan pasien terhadap program restriksi cairan yang sedang dijalankan. Gangguan ketidaknyamanan ini perlu adanya tindakan mandiri perawat. Dengan mempertimbangakan adanya pembatasan cairan dan sodium yang direkomendasikan pada pasien CHF, maka perangsangan saliva dapat digunakan untuk menjaga mukosa mulut tetap lembab, mengurangi keluhan haus dan mulut kering. Salah satu dari tindakan tersebut dapat dipilih oleh perawat sebagai tindakan mandiri yang disesuaikan dengan kesukaan dan toleransi pasien terhadap bahan yang digunakan. Diantara beberapa bahan tersebut tersebut, fruit frozen dipilih berdasarkan rekomendasi bahwa pasien dengan CHF dapat mengkonsumsi semua buah-buahan dan sayuran segar. ${ }^{5,9,14}$

Berdasarkan hal tersebut maka peneliti merasa tertarik untuk melakukan penelitian tentang efektivitas fruit frozen terhadap pasien CHF yang mengalami keluhan haus atau mulut kering akibat program restriksi cairan.

\section{METODE}

Penelitian ini menggunakan desain quasi experiment dengan pendekatan One group pretest- posttest design. Populasi dalam penelitian ini adalah semua pasien dengan diagnosa medis CHF di ruang ruang UPJ RSUP Dr. Kariadi Semarang sebanyak 30 orang dan teknik pengambilan sampel menggunakan teknik purposive sampling yang berjumlah 30 orang.

Instrumen yang digunakan dalam peneilitian ini berupa Visual Analogue Scale untuk rasa haus dan mulut kering yang menampilkan tingkatan rasa haus dan mulut kering dengan rentang skor 1-10 dan klasifikasinya dalam bentuk lembar checklist untuk mengetahui lebih mendalam tentang tingkat keluhan rasa haus dan mulut kering pada pasien CHF.

Analisis data dalam penelitian ini menggunakan analisis univariat dan bivariat. Analisis univariat dalam penelitian ini meliputi hasil distribusi frekuensi dan persentase dari masing-masing karakteristik dan variabel yang diteliti yaitu meliputi karaktristik responden (usia, jenis kelamin, dan kelas NYHA), keluhan rasa haus dan mulut kering sebelum diberikan fruit frozen serta keluhan rasa haus dan mulut kering sesudah diberikan fruit frozen. Sebelum dilakukan analisis bivariat data terlebih dahulu dilakukan uji normalitas data dengan memnggunakan uji Saphiro Wilk. Analisis bivariat untuk mengetahui efektivitas fruit frozen terhadap keluhan rasa haus dalam penelitian ini digunakan uji Wilcoxon, dan untuk mengetahui efektivitas fruit frozen terhadap keluhan mulut kering paired $t$-test. 


\section{HASIL}

Tingkat Rasa Haus dan Mulut Kering Responden Sebelum Diberikan Fruit Frozen

Tabel 1 menunjukkan bahwa sebagian besar responden mengalami keluhan rasa haus yang sedang yaitu sebanyak 22 orang $(73,3 \%)$, dan responden yang mengalami keluhan mulut kering sebagian besar adalah cukup kering yaitu sebanyak 21 orang $(70,0 \%)$.

Tingkat Rasa haus dan mulut kering Responden Setelah Diberikan Fruit frozen

Tabel 2 menunjukkan bahwa sebagian besar responden sesudah diberikan fruit frozen mengalami keluhan rasa haus yang sedang yaitu sebanyak 21 orang $(70,0 \%)$, dan yang mengalami keluhan mulut kering sebagian besar adalah cukup kering yaitu sebanyak 21 orang $(70,0 \%)$.

\begin{tabular}{|c|c|c|}
\hline \multicolumn{3}{|c|}{$\begin{array}{l}\text { Distribusi frekuensi responden berdasarkan } \\
\text { tingkat rasa haus dan mulut kering responden } \\
\text { sebelum diberikan fruit frozen di ruang UPJ } \\
\text { RSUP Dr. Kariadi Semarang, } 2013(n=30)\end{array}$} \\
\hline Variabel & $\begin{array}{l}\text { Jumlah } \\
(n=30)\end{array}$ & $\begin{array}{c}\text { Persentase } \\
\text { (\%) }\end{array}$ \\
\hline \multicolumn{3}{|l|}{ Rasa Haus } \\
\hline Haus Sedang & 22 & 73,3 \\
\hline Haus Berat & 8 & 26,7 \\
\hline \multicolumn{3}{|l|}{ Mulut Kering } \\
\hline Agak kering & 2 & 6,7 \\
\hline Cukup kering & 21 & 70,0 \\
\hline Sangat kering & 7 & 23,3 \\
\hline
\end{tabular}

Efektivitas Fruit Frozen terhadap Keluhan Rasa haus pada Pasien CHF yang menjalani restriksi cairan

Tabel 3 menunjukkan bahwa berdasarkan hasil uji Wilcoxon didapatkan rata-rata tingkat rasa haus responden setelah diberikan fruit frozen lebih kecil yaitu sebesar 4,403 dibandingkan dengan tingkat rasa haus sebelum diberikan fruit frozen yaitu sebesar 5,77. Analisis hasil penelitian dengan uji Wilcoxon diperoleh $p=0,000$ $<(0,05)$ sehingga dapat disimpulkan bahwa ada efektivitas yang signifikan antara tingkat rasa haus sebelum dan sesudah diberikan fruit frozen pada pasien $\mathrm{CHF}$ yang menjalani restriksi cairan.

Efektivitas Fruit Frozen terhadap Keluhan mulut kering pada Pasien CHF yang menjalani restriksi cairan Tabel 43 menunjukkan bahwa berdasarkan hasil uji Paired T-Test didapatkan rata-rata tingkat mulut kering

\section{TABEL 2 \\ Distribusi frekuensi responden berdasarkan tingkat rasa haus dan mulut kering responden setelah diberikan fruit frozen di ruang UPJ RSUP Dr. Kariadi Semarang, 2013 ( $n=30)$}

\begin{tabular}{ccc} 
Variabel & Jumlah & $\begin{array}{c}\text { Persentase } \\
(\boldsymbol{n}=30)\end{array}$ \\
\hline
\end{tabular}

Rasa Haus

$\begin{array}{lcc}\text { Haus Ringan } & 8 & 26,7 \\ \text { Haus Sedang } & 21 & 70,0 \\ \text { Haus Berat } & 1 & 3,3 \\ \text { Mulut Kering } & 9 & 30,0 \\ \text { Agak kering } & 21 & 70,0 \\ \text { Cukup kering } & & \end{array}$

TABEL 3

Efektivitas fruit frozen terhadap tingkat rasa haus pada pasien CHF yang menjalani restriksi cairan di ruang UPJ RSUP Dr. Kariadi Semarang, Desember $2013(n=30)$

\begin{tabular}{lcccc} 
Variabel & $\mathbf{n}$ & Mean (rata-rata) & Std. Deviasi & $\boldsymbol{p}$ \\
\hline Sebelum & 30 & 5,77 & 1,135 & 0,000 \\
Sesudah & 30 & 4,403 & 0,9063 & \\
\hline
\end{tabular}

TABEL 4

Efektivitas fruit frozen terhadap tingkat mulut kering pada pasien CHF yang menjalani restriksi cairan di Ruang UPJ RSUP Dr. Kariadi Semarang, Desember $2013(n=30)$

\begin{tabular}{lcccc|} 
Variabel & $\mathbf{n}$ & Mean (rata-rata) & Std. Deviasi & $\boldsymbol{p}$ \\
\hline Sebelum & 30 & 5,53 & 1,224 & 0,000 \\
Sesudah & 30 & 4,345 & 0,8182 & \\
\hline
\end{tabular}


responden setelah diberikan fruit frozen lebih kecil yaitu sebesar 4,345 dibandingkan dengan tingkat mulut kering sebelum diberikan fruit frozen yaitu sebesar 5,53. Analisis hasil penelitian dengan uji Paired T-Test diperoleh $p=0,000<(0,05)$ sehingga dapat disimpulkan bahwa ada efektivitas yang signifikan antara tingkat mulut kering sebelum dan sesudah diberikan fruit frozen pada pasien CHF yang menjalani restriksi cairan.

\section{PEMBAHASAN}

\section{Tingkat Rasa haus dan mulut kering pasien $\mathrm{CHF}$ yang menjalani restriksi cairan sebelum diberikan fruit frozen}

Hasil penelitian ini menunjukkan gambaran tingkat rasa haus dan mulut kering responden sebelum diberikan fruit frozen dengan rata-rata untuk rasa haus 5,77 dan dengan tingkat rasa haus terendah 4 dan tertinggi adalah 8. Secara kategorik tingkat rasa haus responden sebelum diberikan fruit frozen sebagian besar mengalami haus sedang yaitu sebanyak 22 orang $(73,3 \%)$, dan yang mengalami haus berat sebanyak 8 orang $(36,7 \%)$. Sedangkan untuk rata-rata tingkat mulut kering 5,53 dan dengan tingkat mulut kering terendah 3 dan tertinggi adalah 8. Secara kategorik tingkat mulut kering responden sebelum diberikan fruit frozen sebagian besar mengalami keluhan cukup kering yaitu sebanyak 21 orang $(70,0 \%)$, yang mengalami keluhan sangat keting sebanyak 7 orang $(23,3 \%)$, dan yang mengalami keluhan agak kering sebanyak 2 orang $(6,7 \%)$.

Hal ini sesuai dengan penelitian yang dilakukan oleh Mubarak (2010), dengan hasil bahwa gambaran tingkat rasa haus dan mulut kering pada pasien gagal jantung dengan pembatasan cairan didapatkan hasil bahwa sebagian besar adalah mengalami rasa haus dan mulut kering yang berat dan sedang yaitu sebanyak $(63,3 \%)$. Penelitian lain yang dilakukan oleh Mickey (2009), dengan hasil bahwa tingkat mulut kering pasien yang mendapatkan terapi obat golongan ACE Inhibitor dan Beta Bloker sebagian besar adalah mengalami keluhan mulut cukup kering yaitu sebanyak (57,9\%).

Beberapa hasil penelitian ini menurut peneliti dimungkinkan karena pada pasien dengan gangguan hemodinamik, neurohormonal, fungsi jantung dan fungsi ginjal yang normal, peningkatan total volume darah akan menyebabkan peningkatan jumlah natrium dan air yang diekskresikan oleh ginjal. Pasien dengan CHF, jumlah total volume darah tidak lantas menyebabkan peningkatan ekskresi air dan natrium oleh ginjal. Pasien dengan CHF juga mengalami penurunan kardiak output yang menyebabkan penurunan perfusi organ yang akan direspon oleh tubuh dengan meningkatkan volume cairan tubuh melalui mekanisme sistem Renin-Angiotensin-Aldosteron. Angiotensin II memiliki beberapa efek fisiologi antara lain vasokonstriksi pembuluh darah ginjal dan perifer, menstimulasi sistem saraf simpatis dan meningkatkan rasa haus. ${ }^{1,4,15}$

Keluhan rasa haus dan mulut kering dapat menimbulkan ketidaknyamanan dan memicu ketidakpatuhan pasien terhadap program restriksi cairan yang sedang dijalankan. Bila hal ini terus berlanjut, maka dapat memicu keadaan hipervolemia tanpa disadari oleh pasien. Keadaan hipervolemia akan berkontribusi terhadap memburuknya gejala dan progress penyakit serta outcome pasien dengan $\mathrm{CHF}^{2}{ }^{2}$

\section{Tingkat rasa haus dan mulut kering pasien $\mathrm{CHF}$ yang menjalani restriksi cairan setelah diberikan fruit frozen}

Hasil penelitian ini menunjukkan gambaran tingkat rasa haus dan mulut kering responden setelah diberikan fruit frozen dengan rata-rata untuk rasa haus 4,403 dan dengan tingkat rasa haus terendah 3,1 dan tertinggi adalah 7,2. Secara kategorik tingkat rasa haus responden setelah diberikan fruit frozen sebagian besar mengalami haus sedang yaitu sebanyak 21 orang $(70,0 \%)$, yang mengalami haus ringan sebanyak 8 orang $(26,7 \%)$, dan yang mengalami haus berat sebanyak 1 orang $(3,3 \%)$. Sedangkan untuk rata-rata tingkat mulut kering setelah diberikan fruit frozen 4,345 dan dengan tingkat mulut kering terendah 2,9 dan tertinggi adalah 6,2. Secara kategorik tingkat mulut kering responden setelah diberikan fruit frozen sebagian besar mengalami keluhan cukup kering yaitu sebanyak 21 orang $(70,0 \%)$, dan yang mengalami keluhan agak kering sebanyak 9 orang $(30,0 \%)$.

Hal ini sesuai dengan penelitian yang dilakukan oleh Jackson (2009), dengan hasil bahwa gambaran tingkat keluhan haus pada pasien yang menjani program restriksi cairan setelah diberikan fruit frozen sebagian besar adalah mengalami haus ringan yaitu sebanyak $56,7 \%$.

Hal ini sesuai dengan pendapat Weiland (2011), yang menyatakan bahwa ada beberapa tindakan untuk mengatasi keluhan haus dan mulut kering. Cara untuk mengurangi rasa haus antara lain dengan menggosok gigi dan berkumur lebih sering, menjaga mulut tetap sejuk dengan cold mouthwash. Perangsangan saliva juga dapat dilakukan mencampur air minum dengan lemon, merangsang pengeluaran saliva dengan permen karet, permen keras, spray untuk saliva, menghisap potongan lemon, jeruk nipis dan makan buah serta sayuran yang didinginkan atau dibekukan. Untuk buah yang dibekukan buah anggur atau strawberry akan lebih baik. $^{28}$ 
Efektivitas fruit frozen terhadap keluhan rasa haus dan mulut kering pada pasien $\mathrm{CHF}$ yang menjalani program restriksi cairan

Berdasarkan hasil analisis statistik dengan uji Wilcoxon menunjukkan bahwa terdapat efektivitas yang signifikan antara tingkat rasa haus pasien $\mathrm{CHF}$ yang menjalani restriksi cairan sebelum dan sesudah diberikan fruit frozen. Ini dapat dilihat pada nilai rata-rata (mean) sebelum diberikan fruit frozen sebesar 5,77 dan nilai ratarata (mean) sesudah diberikan fruit frozen sebesar 4,403 dan nilai $p=0,000<0,05$. Dari hasil tersebut dapat disimpulkan bahwa ada efektivitas secara signifikan (bermakna) antara tingkat rasa haus pasien CHF yang menjalani restriksi cairan sebelum dan sesudah diberikan fruit frozen di Ruang UPJ RSUP Dr. Kariadi Semarang.

Hasil analisis statistik efektivitas fruit frozen terhadap keluhan mulut kering dengan uji paired t-test menunjukkan bahwa terdapat efektivitas yang signifikan antara keluhan mulut kering pasien CHF yang menjalani restriksi cairan sebelum dan sesudah diberikan fruit frozen. Ini dapat dilihat pada nilai rata-rata (mean) sebelum diberikan fruit frozen sebesar 5,53 dan nilai ratarata (mean) sesudah diberikan fruit frozen sebesar 4,345 dan nilai $p=0,000<0,05$. Dari hasil tersebut dapat disimpulkan bahwa ada efektivitas yang signifikan (bermakna) antara keluhan mulut kering pasien $\mathrm{CHF}$ yang menjalani restriksi cairan sebelum dan sesudah diberikan fruit frozen di Ruang UPJ RSUP Dr. Kariadi Semarang.

Berdasarkan hasil penelitian di atas, menurut peneliti dimungkinkan karena dengan adanya fruit frozen maka dapat meningkatkan produksi saliva pada pasien. Peningkatan produksi saliva ini akan membuat mukosa bibir menjadi lembab dan mengurangi sensasi rasa haus dan mulut kering yang dialami pasien akibat program restriksi cairan dan pemberian obat-obat diuretik, ECE Inhibitor, dan Beta Bloker. Berkurangnya rasa haus dan mulut kering pada pasien diharapkan dapat mengurangi keinginan pasien untuk minum, sehingga program restriksi cairan yang dijalani akan berhasil dan mempercepat proses penyembuhan.

Rasa haus dalam hal ini bisa berkurang karena adanya perangsangan saliva dengan fruit frozen yang mengakibatkan pengaktifan reflek masticatory dan gustatory. Masticatory mekanisme disini adalah adanya kegiatan mengunyah yang dilakukan pasien terhadap buah Strawbery. Gustatory mekanisme disini adalah adanya perangsangan acid dari kandungan strawbery. Kedua mekanisme ini yang menyebabkan peningkatan pengeluaran saliva dan membuat rasa haus dan mulut kering pasien mengalami penurunan. Hal ini bisa terjadi karena adanya saliva yang ditelan oleh pasien sehingga mampu membasahi mukosa tenggorokan pasien. 2

\section{SIMPULAN}

Tingkat rasa haus sebelum diberikan fruit frozen sebagian besar mengalami keluhan rasa haus yang sedang, sedangkan responden yang mengalami keluhan mulut kering sebagian besar adalah cukup kering. Tingkat rasa haus setelah diberikan fruit frozen sebagian besar sebagian besar mengalami keluhan rasa haus yang sedang, dan responden yang mengalami keluhan mulut kering sebagian besar adalah cukup kering. Ada efektivitas yang signifikan antara tingkat rasa haus dan mulut kering sebelum dan sesudah diberikan fruit frozen pada pasien CHF yang menjalani restriksi cairan. Disarankan bagi rumah sakit agar dapat melakukan kerjasama dengan instalasi gizi dalam pengadaan fruit frozen untuk pasien $\mathrm{CHF}$ dengan program restriksi cairan.

\section{Ucapan Terimaksih}

Peneliti memberikan apresiasi yang setinggi-tingginya kepada RSUP Dr. Kariadi Semarang yang telah memberikan kesempatan kepada peneliti untuk melaksanan penelitian.

\section{DAFTAR PUSTAKA}

1. Albert, Nancy M. (2012). Fluid Management Strategies in Heart Failure. Journal of critical nurse. Vol.32, No 2, April 2012.

2. Androne, et al. (2004). Relation of Unrecognize Hypervolemia in Chronic Heart Failure to Clinical Status, Hemodynamics, and Patient Outcomes. The American Journal of Cardiology. Vol.93:1254-1259.

3. Arikunto, S. (2006). Prosedur Penelitian Suatu Pendekatan Praktik. Jakarta: Rineka Cipta.

4. Bots, Casper P. (2005). Chewing Gum and a Saliva Substitues Alliviate Thirst and Xorostomia Patients on Hemodyalisis. Nephrology Dyalisis Transplantation. Vol 20:578-584.

5. Depkes RI. (2009). Keputusan Mentri Kesehatan Republik Indonesia tentang Pedoman Pengendalian Penyakit Jantung dan Pembuluh Darah.

6. Dixon, Suzanne. (2012). Dry Mouth and/or Thick Saliva. Diakses melalui http://ndt.oxfordjournal.org/

7. Gibbs et al. (2000). ABC of Heart Failure Non-Drug Menegement. BMJ 2000;320:366-9.

8. Hamidi. (2007). Metode Penelitian dan Teori Komunikasi. Malang: UMM Press.

9. Harley, Inggrid. (2012). Symptom Management Guide-toPractice: Oral Care. Cancer care ontario.

10. Hidayat, AA. (2003). Riset Keperawatan dan Teknik Penulisan Ilmiah. Jakarta: Salemba Medika.

11. Irfan Arief. (2009). Jantung Koroner Jangan Sampai Berujung Gagal Jantung. Diakses tanggal 12 April 2013 melalui http://www.pjnhk.go.id/content/view

12. Instalasi Gizi Perjan RS Dr. Cipto Mangunkusumo dan Asosiasi Dietisien Indonesia (2004). Penuntun Diet. Jakarta: Gramedia.

13. Jacobsson, Anna. (2012). Malnutrition in Patients Suffering From Chongestive Heart Failure; The Nurse's Care. The european journal of heart failure. Vol.3:449-456.

14. Lichtenstein et al. (2006). Diet and Lifestyle Recomendation Revision 2006: Scientific Statement From The American Heart Association Nutrission Committee. Circulation.2006;114:82-96. 
15. Lilly, Leonard. S. (2011). Pathophisiology of Herat Disease: a Collaborative Project of Medical Student and Faculty. 5th ed. Philadelphia: lippincott williams\&wilkins.

16. Lindenfeld, J et al. (2010). Execitive Summary: HFSA 2010 Comprehensive Heart Failure Practice Guideline. Journal of Cardiac failure Vol.16 No.6 tahun 2010.

17. Klabunde, Richard. (2007). Cardiovasculary Physiology concepts. Diakses melallui http://www.cvphysiology.com/ blood\%20pressure/BP001.htm

18. Karami-Nogourani M, Kowsari-Isfahan R, Hoseini-Beheshti M. (2011). The Effect of Chewing Gum's Flavour on Sallivarryflow Rate and pH. Dent Res J 2011;8:S71-5.

19. McKinley, J Michael. (2004). The Phisiological Regulation of Thirst and Fluid intake. Physiologi Journal 2004;19:1-6.

20. Martini. (2001). Fundamentals of Anatomy and Physiology. Fifth Edition. Upper Sadle River, New Jersey: Prentice-Hall Inc.

21. Nation Heart Foun dation of Australia and Cardiac Society of Australia and New Zeland (2011). Quick Reference Guide. Diagnosis and Management of Chronic Heart Failure. Update October 2011

22. Notoatmodjo, S. (2010). Metodologi Penelitian Kesehatan. Jakarta: Rineka Cipta.
23. Nursalam. (2008). Konsep dan Penerapan Metodologi Penelitian Ilmu Keperawatan Edisi 2. Jakarta: Salemba Medika.

24. Riyanto, A. (2009). Pengolahan dan Analisis Data Kesehatan.Yogyakarta: Nuha Medika.

25. Sugiono. (2011). Statistika untuk Penelitian. Bandung: Alfabeta.

26. The Kidney Foundation of Canada. (2010). Potassium and Chronic Kidney Disease. The Canadian Association of Nephrologi Dietitans.

27. Wang G, Zhang Z, Ayala C, Wall HK, Fang J. Costs of heart failure-related hospitalizations in patients aged 18-64 years. Am J Manang Care. 2010;16(10):769-7628.

Weiland, Mary. (2011). Your Heart Disease and Fluid Restriction. Peter Munk Cardiac Centre. 